\title{
Inhibition of Intracellular Degradation Increases Secretion of a Mutant Form of $\alpha$ 1-Antitrypsin Associated with Profound Deficiency
}

\author{
Natalia Novoradovskaya, ${ }^{*}$ JungHwa Lee, ${ }^{\star} \mathrm{Zu}-\mathrm{Xi}$ Yu, ${ }^{\ddagger}$ Victor J. Ferrans, ${ }^{\ddagger}$ and Mark Brantly* \\ *Clinical Studies Section, Pulmonary-Critical Care Medicine Branch, and ${ }^{\ddagger}$ Pathology Section, National Heart, Lung, and Blood Institute, \\ National Institutes of Health, Bethesda, Maryland 20892-1590
}

\begin{abstract}
The mutant $\mathrm{Z}$ form of $\alpha 1$-antitrypsin ( $\alpha 1 \mathrm{AT})$ is responsible for $>95 \%$ of all individuals with $\alpha 1 \mathrm{AT}$ deficiency, an important inherited cause of emphysema and liver disease. Since secreted $\mathrm{Z} \alpha \mathbf{1 A T}$ is a functional antiprotease, we hypothesized that interrupting catabolism of retained $\mathrm{Z} \alpha \mathbf{A T}$ might increase its transport out of cells, causing an increase in extracellular protease protection. Both the protein translation inhibitor cycloheximide and the specific inhibitor of proteasome function, lactacystin, prevented intracellular degradation of $Z \alpha 1 A T$. Moreover, this inhibition of degradation was associated with partial restoration of $Z \alpha 1 \mathrm{AT}$ vesicular transport. This effect was observed in a model system of transfected $\mathrm{CHO}$ cells as well as in human alveolar macrophages synthesizing $\mathrm{Z} \alpha 1 \mathrm{AT}$. This study supports the hypothesis that altering the intracellular fate of a mutant protein may be an option in the treatment of diseases associated with misfolded but potentially functional proteins. ( $J$. Clin. Invest. 1998. 101:2693-2701.) Key words: $\alpha 1$-antitrypsin • degradation • proteasome • cirrhosis • emphysema
\end{abstract}

\section{Introduction}

$\alpha 1$-Antitrypsin $(\alpha 1 \mathrm{AT})^{1}$ deficiency, an autosomal recessively inherited disease, affects up to 1 in 2,500 Caucasians. The classic disorder is associated with early onset of emphysema and premature death. Less frequently, $\alpha 1 \mathrm{AT}$ deficiency causes severe liver disease, particularly in children. Currently liver transplant is the only effective therapy for these children $(1,2)$. Individuals with intermediate $\alpha 1 \mathrm{AT}$ levels appear entirely normal. $\alpha 1 \mathrm{AT}$, a glycoprotein secreted in abundance by hepatocytes and mononuclear phagocytes, serves as the major serum antiprotease responsible for critical protease-antiprotease balance in the lung and elsewhere $(1,2)$.

Although there are more than 30 variants that cause $\alpha 1 \mathrm{AT}$ deficiency, the $Z$ form exists in $>95 \%$ of all $\alpha 1 \mathrm{AT}$-deficient individuals (1-3). The $\mathrm{Z}$ protein differs from the normal $\mathrm{M}$

Address correspondence to Dr. Mark Brantly, Pulmonary-Critical Care Medicine Branch, 10 Center Drive, MSC-1590, Building 10, Room 6D03, National Institutes of Health, National Heart, Lung, and Blood Institute, Bethesda, Maryland 20892-1590. Phone: 301496-5020; FAX: 301-435-2883; E-mail: aaron@helix.nih.gov

Received for publication 2 May 1997 and accepted in revised form 13 April 1998.

1. Abbreviation used in this paper: $\alpha 1 \mathrm{AT}, \alpha 1$-antitrypsin.

The Journal of Clinical Investigation

Volume 101, Number 12, June 1998, 2693-2701

http://www.jci.org variant in the replacement of a glutamic acid by lysine near the base of the reactive site loop; this replacement disturbs a salt bridge between two strands in $\beta$ sheet A of $\alpha 1 \mathrm{AT}(1,4-8)$. The amino acid substitution also leads to a delay in protein folding and subsequent linkage of the $\mathrm{Z} \alpha 1 \mathrm{AT}$ molecules via loopsheet polymerization (2,7-9). The intracellular fate of $Z \alpha 1 \mathrm{AT}$ has been extensively studied by several laboratories $(5,7,10$ 14). Although $\sim 15 \%$ of $\mathrm{Z} \alpha 1 \mathrm{AT}$ is secreted and has half the function of normal $\mathrm{M} \alpha 1 \mathrm{AT}$, the vast majority remains in the RER and is degraded before entering the Golgi apparatus (1, $2,5,6,12-17)$. Intracellular degradation of $\mathrm{Z} \alpha 1 \mathrm{AT}$ in a transfected rat hepatocyte system is nonlysosomal, energy-dependent, and sensitive to inhibitors of protein translation $(12,15)$. Recently, inhibitors of multicatalytic proteasomes have been implicated in the catabolism of intracellular $\mathrm{Z} \alpha 1 \mathrm{AT}$ in transfected human fibroblasts (18). Several types of $\alpha 1 \mathrm{AT}$-secreting cells have been used to determine the molecular basis of $\alpha 1 \mathrm{AT}$ variants, including transfected or infected mouse hepatoma cells, COS1 cells, NIH 3 T3 cells, human fibroblasts, alveolar macrophages, and recently, $\mathrm{CHO}$ cells $(5,10,12,13,16,18$ 20). CHO cells do not synthesize $\alpha 1 \mathrm{AT}$ mRNA, and have been used extensively in studies of glycoprotein transport $(10,19)$. In this study, we demonstrate increased secretion of functional $\mathrm{Z} \alpha 1 \mathrm{AT}$ after inhibition of its intracellular degradation in a model CHO cell system and human alveolar macrophages expressing the $\mathrm{Z} \alpha 1 \mathrm{AT}$ gene.

\section{Methods}

Plasmid construction and in vitro model system. To determine the molecular mechanisms associated with the profound reduction of secreted $\mathrm{Z} \alpha 1 \mathrm{AT}$, we used CHO cells (CCL61; American Type Culture Collection, Rockville, MD) transfected with eukaryotic expression vectors $\mathrm{pRc} / \mathrm{RSV}$ (Invitrogen, San Diego, CA) containing the normal $\mathrm{M}$ or $\mathrm{Z}$ gene. Oligonucleotide site-directed mutagenesis and PCR were used to generate the $\mathrm{Z}$ mutation using the normal $\alpha 1 \mathrm{AT}$ cDNA as a template. Intron II of the $\alpha 1 \mathrm{AT}$ genomic sequence was introduced into its native position to increase gene expression. Transfected cells were selected using G418 (GIBCO BRL, Gaithersburg, $\mathrm{MD}$ ), and G418-resistant colonies were pooled to establish a polyclonal population of transfected cells. For all experiments, the transfected cells were at $80-90 \%$ confluence $(19,20)$.

Metabolic labeling studies. Nearly confluent monolayers of $\mathrm{CHO}$ cells expressing $\mathrm{Z}$ or $\mathrm{M} \alpha 1 \mathrm{AT}$ in $100-\mathrm{mm}$-diameter culture dishes were incubated for $30 \mathrm{~min}$ with $\left[{ }^{35} \mathrm{~S}\right]$ methionine $(200-500 \mu \mathrm{Ci} / \mathrm{ml}$ of medium; ICN Pharmaceuticals Inc., Irvine, CA), and were then chased for 0-12 h by incubation in $3 \mathrm{ml}$ of Ham's F-12 (Biofluids, Inc., Rockville, MD) with $10 \%$ FCS containing a fivefold excess of unlabeled methionine. Subconfluent culture plates with similar numbers of cells were labeled with the same amount of $\left[{ }^{35}\right.$ S $]$ methionine, and the radiolabeled plates of cells were randomly chosen for either treatment or no treatment with cycloheximide. To determine rates and mechanisms of intracellular degradation, the following compounds were included in the chase medium: cycloheximide $(50 \mu \mathrm{g} / \mathrm{ml})$, an inhibitor of protein synthesis, or the metabolic poisons: $40 \mathrm{mM} \mathrm{NaN}_{3}$, $10 \mathrm{mM} \mathrm{NaF}, 5 \mathrm{mM}$ 2,4-dinitrophenol, and $10 \mathrm{mM}$ 2-deoxy-D-glucose. 
Brefeldin A ( $2 \mu \mathrm{g} / \mathrm{ml})$, an inhibitor of normal RER-to-Golgi transport, or inhibitors of lysosomal function, $50 \mathrm{mM} \mathrm{NH}_{4} \mathrm{Cl}, 0.1 \mathrm{mM}$ chloroquine, $0.1 \mathrm{mg} / \mathrm{ml}$ leupeptin, or $10^{-5} \mathrm{M}$ colchicine (Sigma Chemical Co., St. Louis, MO), were present for the entire labeling and chase period $(12,21)$. Alveolar macrophages obtained from bronchoalveolar lavage of individuals with PI* $\mathrm{Z} \alpha 1 \mathrm{AT}$ deficiency evaluated at the National Institutes of Health Clinical Center as part of an institutional review board approved protocol. Alveolar macrophages were incubated for $20 \mathrm{~h}$ in 100 -mm-diameter culture dishes $\left(7.5 \times 10^{6}\right.$ cells) in RPMI 1640 medium (Biofluids, Inc.) with $10 \%$ FCS, pulseradiolabeled with $\left[{ }^{35} \mathrm{~S}\right]$ methionine $(500 \mu \mathrm{Ci} / \mathrm{ml}$ of medium $)$ for $30 \mathrm{~min}$ at $37^{\circ} \mathrm{C}$, and chased for up to $6 \mathrm{~h}$ with or without $50 \mu \mathrm{g} / \mathrm{ml}$ cycloheximide. Alveolar macrophages and $\mathrm{CHO}$ cells were treated with 10 $\mu \mathrm{M}$ lactacystin for $2 \mathrm{~h}$ before pulse-radiolabeling studies, and were maintained at the same concentration throughout the pulse and chase periods (22-24). Cells were harvested in a total volume $1.25 \mathrm{ml}$ of lysis buffer ( $1 \%$ Triton X-100, $0.5 \%$ sodium deoxycholate, $10 \mathrm{mM}$ EDTA, and $1 \mathrm{mM}$ PMSF in $1 \times$ PBS, $\mathrm{pH} 7.6$; Sigma Chemical Co.), frozen in dry ice, and centrifuged to precipitate cell debris. $\alpha 1 \mathrm{AT}$ was immunoprecipitated from cell lysate or medium using rabbit antihuman $\alpha 1 \mathrm{AT}$ antibodies (Accurate Chemical and Scientific Co., Westbury, NY; or DAKO Corp., Carpinteria, CA) bound to protein A Sepharose CL-4B (Pharmacia Biotech AB, Uppsala, Sweden). Immunocomplexes were washed, suspended in $50 \mu \mathrm{l}$ of sample buffer (63 mM Tris- $\mathrm{HCl}, 2 \%$ SDS, 5\% $\beta$-mercaptoethanol, 10\% glycerol, and $0.0025 \%$ bromophenol blue), heated at $95^{\circ} \mathrm{C}$ for $5 \mathrm{~min}$, and analyzed using SDS Tris-glycine 4-12\% PAGE (Novex, San Diego, CA; $5,19,20)$. Radiolabeled $\alpha 1 \mathrm{AT}$ was detected by autoradiography and quantified using a densitometer (Molecular Dynamics, Sunnyvale, CA). Immunoprecipitates from lysates after $1 \mathrm{~h}$ of chase were treated with $2 \mathrm{mU}$ endoglycosidase-H (Oxford Glyco Sciences, Inc., Wakefield, MA) at $37^{\circ} \mathrm{C}$ for $20 \mathrm{~h}$. Similar immunoprecipitates were analyzed without endoglycosidase-H treatment $(19,20)$.

Viability of cultured cells was determined by trypan blue exclusion and/or by counting the number of detached cells. Throughout the metabolic studies, CHO cell and alveolar macrophage death did not exceed $1 \%$ of total cell number.

To determine if lactacystin and cycloheximide caused cytotoxicmediated leakage of normally cytosolic proteins, the $29-\mathrm{kD}$ intracellular resident protein neomycin phosphotransferase, the gene product that confers $\mathrm{G} 418$ resistance in the transfected $\mathrm{CHO}$ cell line, was used as a marker for extracellular leakage of cytosolic protein content. CHO cells expressing $\mathrm{Z} \alpha 1 \mathrm{AT}$ were incubated in the presence of $50 \mu \mathrm{g} / \mathrm{ml}$ cycloheximide or $10 \mu \mathrm{M}$ lactacystin for $0-10 \mathrm{~h}$ under conditions identical to those used to characterize the intra- and extracellular fate of $\alpha 1 \mathrm{AT}$. Cell lysates and medium were immunoprecipitated with antibody to the $29-\mathrm{kD}$ intracellular resident protein neomycin phosphotransferase (5 Prime $\rightarrow 3$ Prime Inc., Boulder, CO) and separated according to apparent molecular mass by a 4-12\% SDS-PAGE. No radiolabeled neomycin phosphotransferase was detected in medium of transfected $\mathrm{CHO}$ cells under conditions used to characterize the intracellular fate of $\mathrm{Z} \alpha 1 \mathrm{AT}$, indicating that cytotoxicity and intracellular release of cytosolic proteins did not contribute to the total amount of extracellular $\alpha 1 \mathrm{AT}$. In addition, in all experiments involving transfected $\mathrm{CHO}$ cells, no intracellular high-mannose $50-\mathrm{kD}$ $\alpha 1 \mathrm{AT}$ was detected in the medium.

Quantitative assessment of intra- and extracellular $\alpha 1 A T$. To evaluate the effect of cycloheximide on $\alpha 1 \mathrm{AT}$ intracellular transport in $\mathrm{CHO}$ cells, cells were lysed in a total volume $1.25 \mathrm{ml}$ of lysis buffer, and $\alpha 1 \mathrm{AT}$ was isolated by immunoprecipitating $0.5 \mathrm{ml}$ of lysate $(40 \%$ of total). The amount of $\alpha 1 \mathrm{AT}$ secreted by $\mathrm{CHO}$ cells was determined by immunoprecipitating $0.5 \mathrm{ml}$ medium from a total volume of $3 \mathrm{ml}(17 \%$ of total). The amount of intra- and extracellular $\alpha 1 \mathrm{AT}$ from alveolar macrophages treated with either lactacystin or cylcoheximide was determined by immunoprecipitating $1.25 \mathrm{ml}(100 \%$ of total) lysate and $3 \mathrm{ml}$ medium ( $100 \%$ of total). Since transfected $\mathrm{CHO}$ cells synthesize five to tenfold more $\alpha 1 \mathrm{AT}$ than do alveolar macrophages, the amount of cell lysate and medium from $\mathrm{CHO}$ cells used to evaluate the effect of lactacystin was reduced to $0.25 \mathrm{ml}$ and $0.6 \mathrm{ml}$, respectively ( $20 \%$ of total) to assure that all bands on the autoradiograms were in a similar range. The total intracellular and extracellular $\alpha 1 \mathrm{AT}$ was estimated by multiplying the band densities by the appropriate ratio of medium or lysate total volume. Experiments that quantified the effects of cycloheximide and lactacystin on alveolar macrophages and $\mathrm{CHO}$ cells were performed in triplicate or more.

Functional assessment of secreted $\alpha 1 A T$. To compare the function of $\mathrm{Z}$ and $\mathrm{M} \alpha 1 \mathrm{AT}$, the samples of medium $(0.5 \mathrm{ml})$ after $4 \mathrm{~h}$ of chase with or without treatment with either $50 \mu \mathrm{g} / \mathrm{ml}$ cycloheximide or $10 \mu \mathrm{M}$ lactacystin, were concentrated (Microcon 30; Amicon, Inc., Beverly, MA) to $50 \mu l$, and were incubated with an excess amount of human neutrophil elastase $(0.45 \mathrm{ml}$ of $100 \mathrm{nM}$ neutrophil elastase solution; Athens Research and Technology, Inc., Athens, GA) in $0.1 \mathrm{M}$ Hepes (pH 7.5), $0.5 \mathrm{M} \mathrm{NaCl}$, and $0.1 \%$ Brij 35 for $2 \mathrm{~h}$ at $37^{\circ} \mathrm{C}$. Complex formation was accomplished in slight excess of neutrophil elastase compared with $\alpha 1 \mathrm{AT}$. To generate this complex, we performed a pilot titration experiment using a fixed amount of labeled $\alpha 1 \mathrm{AT}$ with increasing amounts of neutrophil elastase. Using this approach, we were able to titrate formation of complexes without causing nonspecific degradation of the complex by excess neutrophil elastase. Complexes were immediately immunoprecipitated by anti$\alpha 1 \mathrm{AT}$, washed, suspended in $50 \mu \mathrm{l}$ of SDS sample buffer $(63 \mathrm{mM}$ Tris- $\mathrm{HCl}, 2 \%$ SDS, $5 \% \beta$-mercaptoethanol, $10 \%$ glycerol, $0.0025 \%$ bromophenol blue), heated at $95^{\circ} \mathrm{C}$ for $5 \mathrm{~min}$, and subjected to $4-20 \%$ SDS-PAGE.

Immunofluorescence. Transfected cells grown on coverslips were incubated with or without $50 \mu \mathrm{g} / \mathrm{ml}$ cycloheximide or $10 \mu \mathrm{M}$ lactacystin, fixed with $2 \%$ paraformaldehyde, and treated serially with appropriate dilutions of primary antibodies (rabbit anti-human $\alpha 1 \mathrm{AT}$ [Dako Corp.] and mouse anti-BiP [StressGen Biotechnologies Corp., Victoria, British Columbia], or anti-p58 and $\beta$-COP [Sigma Chemical Co.]) and secondary antibodies ([FITC-conjugated goat anti-rabbit and rhodamine-conjugated goat-anti-mouse; Jackson ImmunoResearch Laboratories, Inc., West Grove, PA]) with $0.05 \%$ saponin and $1 \%$ BSA in PBS. Cells were washed, mounted on glass slides, and photographed using a fluorescence microscope (Nikon, Inc., Melville, NY) with a $60 \times$ objective, or with a TCS 4D laser scanning confocal microscope (Leica, Heidelberg, Germany) with a $100 \times$ objective.

Statistical analysis. Statistical analysis was performed using a paired two-tailed $t$ test. Intra- and extracellular $\alpha 1 \mathrm{AT}$ concentrations were expressed as the mean increase over baseline \pm SEM. The determination of half-lives of intracellular $\mathrm{Z}$ and $\mathrm{M} \alpha 1 \mathrm{AT}$ were performed in triplicate or more and are expressed as the mean \pm SEM.

\section{Results}

Vesicular transport of $M$ and $Z \alpha 1 A T$. Using a transfected $\mathrm{CHO}$ cell system, we compared the amount of intra- and extracellular $\alpha 1 \mathrm{AT}$ in M- vs. Z-transfected cells under various conditions. $\mathrm{Z} \alpha 1 \mathrm{AT}$ accumulated in the intracellular compartment in an endoglycosidase $\mathrm{H}$-sensitive, high-mannose oligosaccharide 50-kD form, and was secreted in amounts 4.3-6.7-fold less than those of $\mathrm{M} \alpha 1 \mathrm{AT}$ (Fig. $1, A$ and $B$ ). Since $\mathrm{M}$, and to a lesser extent $\mathrm{Z} \alpha 1 \mathrm{AT}$ are secreted, brefeldin $\mathrm{A}$, a drug that disrupts vesicular transport between the RER and Golgi, was used to evaluate the intracellular half-lives of $\mathrm{M}$ and $\mathrm{Z} \alpha 1 \mathrm{AT}$. Using the best-fit logarithmic curve $\left(\mathrm{r}^{2}>0.95\right)$ on a log-linear plot, the intracellular half-life of Z $\alpha 1 \mathrm{AT}$ in brefeldin A-treated cells $(9.8 \pm 0.6 \mathrm{~h})$ was significantly less than that of $\mathrm{M} \alpha 1 \mathrm{AT}$ $(24 \pm 2.8 \mathrm{~h} ; P=0.005$; see Fig. $1 C)$.

The metabolic inhibitors $\mathrm{NaN}_{3}$ and $\mathrm{NaF}$, or 2,4-dinitrophenol and 2-deoxy-D-glucose, used in combination to block the energy-dependent components of intracellular degradation, reduced degradation of $\mathrm{Z} \alpha 1 \mathrm{AT}$ by $50-60 \%$. Inhibitors of lyso- 


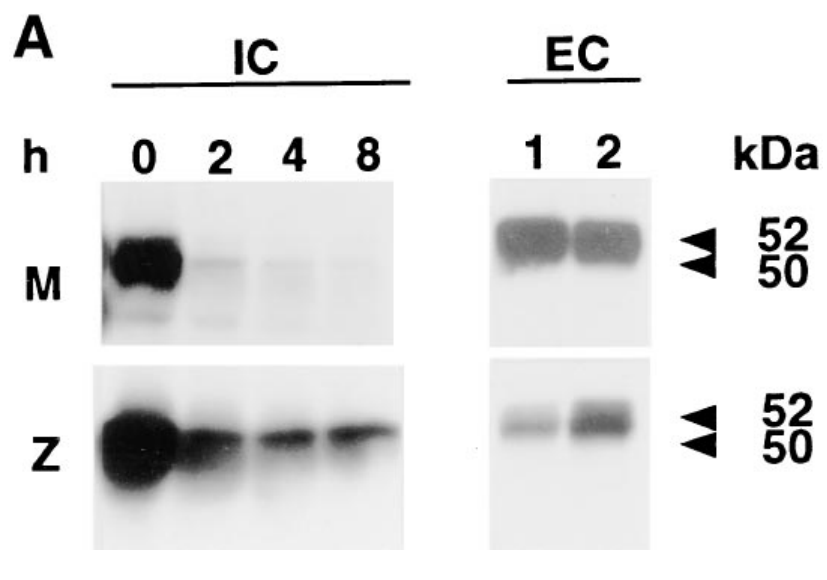

B
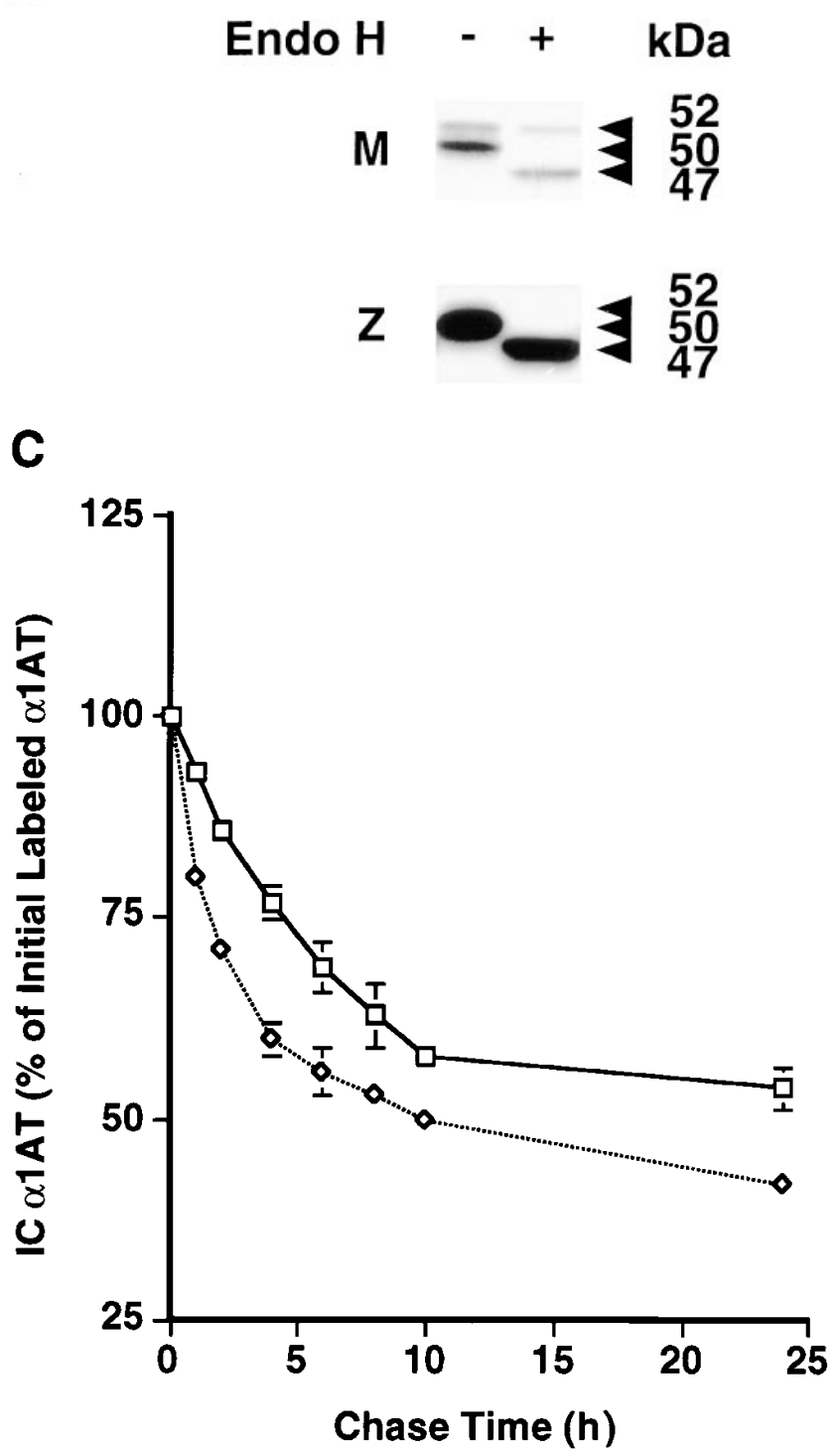

Figure 1. Vesicular transport of normal $(M)$ and $\mathrm{Z} \alpha 1 \mathrm{AT}$ in $\mathrm{CHO}$ cells. $(A)$ SDS-PAGE of radiolabeled intracellular and extracellular (secreted) $\mathrm{M}$ and $\mathrm{Z} \alpha 1 \mathrm{AT}$. (Top) Intracellular (IC) and extracellular (EC) $\alpha 1 \mathrm{AT}$. Each lane represents chase time $(h)$ from $0-8 \mathrm{~h}$ for IC and $1-2 \mathrm{~h}$ for EC. (Left) $\mathrm{M}$ and $\mathrm{Z}$ represent $\mathrm{M}$ and $\mathrm{Z} \alpha 1 \mathrm{AT}$. (Right) The apparent molecular masses $(\mathrm{kD})$ of the fully glycosylated $52-\mathrm{kD}$ somal function, including $\mathrm{NH}_{4} \mathrm{Cl}$, chloroquine, leupeptin, and colchicine, did not affect the rate of $\mathrm{Z} \alpha 1 \mathrm{AT}$ degradation of $\mathrm{Z} \alpha 1 \mathrm{AT}$ (data not shown). Because of its long intracellular half-life, the effect of metabolic and lysosomal protease inhibitors on $\mathrm{M} \alpha 1 \mathrm{AT}$ could not be determined before significant cell death occurred.

Cycloheximide increases secretion of $Z$ and $M \alpha 1 A T$. Cycloheximide treatment of $\mathrm{Z} \alpha 1 \mathrm{AT}$-transfected $\mathrm{CHO}$ cells resulted in a transient increased accumulation of intracellular $\mathrm{Z}$ $\alpha 1$ AT followed by a $2.4 \pm 0.28$-fold increase in its secretion by $8 \mathrm{~h}(P=0.018$; Fig. 2, $A$ and $B)$. Comparison of the total intraand extracellular $\alpha 1 \mathrm{AT}$ at time points after synthesis of the radiolabeled $\alpha 1 \mathrm{AT}$ was completed demonstrated that $>80 \%$ of the newly synthesized $\alpha 1 \mathrm{AT}$ is eventually exported to the extracellular compartment in the presence of cycloheximide. In the absence of cycloheximide, $\sim 25 \%$ of the synthesized $\mathrm{Z}$ $\alpha 1 \mathrm{AT}$ is exported extracellularly (Fig. 2, $C$ and $D$ ). This effect was not limited to cycloheximide, since $\mathrm{Z} \alpha 1 \mathrm{AT}$-expressing $\mathrm{CHO}$ cells treated with puromycin demonstrated similar results (data not shown). While cycloheximide did not measurably increase intracellular $\mathrm{M} \alpha 1 \mathrm{AT}$, its secretion was $\sim 34 \pm$ 9.3\% more than that from untreated cells $(P=0.012$; Fig. $2, E$ and $F)$. The rapid extracellular transport of $\mathrm{M} \alpha 1 \mathrm{AT}(\sim 90$ min) in both cycloheximide-treated and -untreated cells (Fig. $2 F$ ) contrasts with the delay in reaching maximal secretion of $\mathrm{Z} \alpha 1 \mathrm{AT}$ in both cycloheximide-treated and -untreated cells ( $8 \mathrm{~h}$ and $4 \mathrm{~h}$, respectively; Fig. $2 \mathrm{~B}$ ). Interestingly, the intracellular half-life of $\mathrm{Z} \alpha 1 \mathrm{AT}$ after pretreatment with $2 \mu \mathrm{g} / \mathrm{ml}$ brefeldin A plus $50 \mu \mathrm{g} / \mathrm{ml}$ cycloheximide was similar to brefeldin A alone (9.8 and $10 \mathrm{~h}$, respectively).

Cycloheximide increases secretion of functional $Z \alpha 1 A T$. To estimate the functional quantity of extracellular $\mathrm{Z} \alpha 1 \mathrm{AT}$, we compared the amount of SDS-stable complexes formed in the presence of an excess amount of neutrophil elastase, the major $\alpha 1 \mathrm{AT}$ substrate, before and after treatment with cycloheximide. Importantly, secreted $\mathrm{Z} \alpha 1 \mathrm{AT}$ from cycloheximidetreated cells formed SDS-stable complexes with neutrophil elastase in proportions similar to those from untreated cells ( $14 \%$ from untreated cells compared with $15 \%$ from cycloheximide-treated cells) despite an increase in the total extracellular $\alpha 1 \mathrm{AT}$ (Fig. 3). In addition to complex formation, 4-kD Z and $\mathrm{M} \alpha 1 \mathrm{AT} \mathrm{C}$-terminal fragments were identified, and demonstrated neutrophil elastase-mediated cleavage of the P1-P1' bond (Fig. 3). Comparison of the percentages of complexed $\mathrm{M}$ and $\mathrm{Z} \alpha 1 \mathrm{AT}$ showed that $\mathrm{M} \alpha 1 \mathrm{AT}$ formed twice as many complexes with neutrophil elastase in proportions as Z $\alpha 1 \mathrm{AT}$ (30 and $14 \%$, respectively).

Cycloheximide alters intracellular localization of $Z \alpha 1 A T$ in $\mathrm{CHO}$ cells. Intracellular localization using immunofluores-

and high mannose $50-\mathrm{kD}$ forms of $\alpha 1 \mathrm{AT}$. (B) SDS-PAGE of radiolabeled intracellular $\mathrm{M}$ and $\mathrm{Z} \alpha 1 \mathrm{AT}$ digested with endoglycosidase- $\mathrm{H}$. (Top) Intracellular $\alpha 1 \mathrm{AT}$ with $(+)$ or without $(-)$ endoglycosidase- $\mathrm{H}$ (EndoH). (Left) $\mathrm{M}$ and $\mathrm{Z}$ represent $\mathrm{M}$ and $\mathrm{Z} \alpha 1 \mathrm{AT}$. (Right) The molecular masses $(\mathrm{kD})$ of the fully glycosylated $52-\mathrm{kD}$, high-mannose $50-\mathrm{kD}$, and endoglycosidase-H-cleaved $47-\mathrm{kD}$ forms of $\alpha 1 \mathrm{AT}$ after $1 \mathrm{~h}$ of chase. $(C)$ Intracellular half-lives of $\mathrm{M}$ and $\mathrm{Z} \alpha 1 \mathrm{AT}$. Ordinate, \% total radiolabeled intracellular $(I C) \alpha 1 \mathrm{AT}$ after brefeldin A treatment. Abscissa, chase time in hours $(h) . \mathrm{M} \alpha 1 \mathrm{AT}$ is the solid line $(\square)$, and $\mathrm{Z} \alpha 1 \mathrm{AT}$ is dotted line $(\diamond)$. Positive and negative error bars are the SEM. 
A
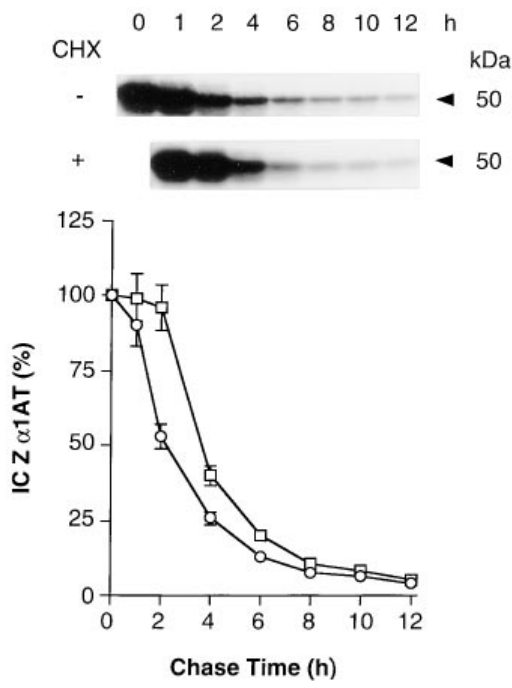

C

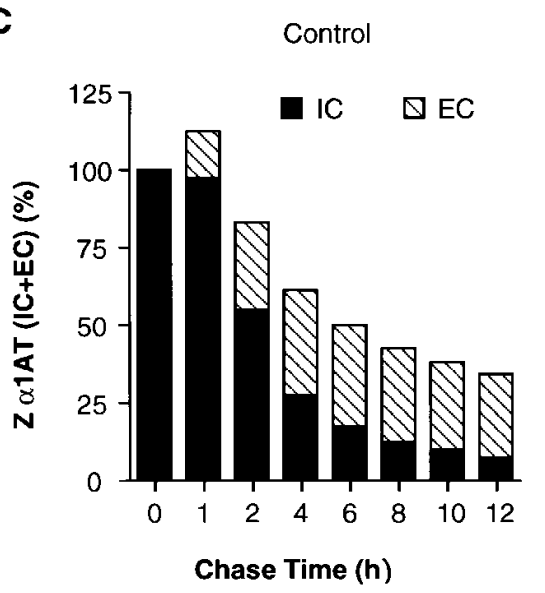

E
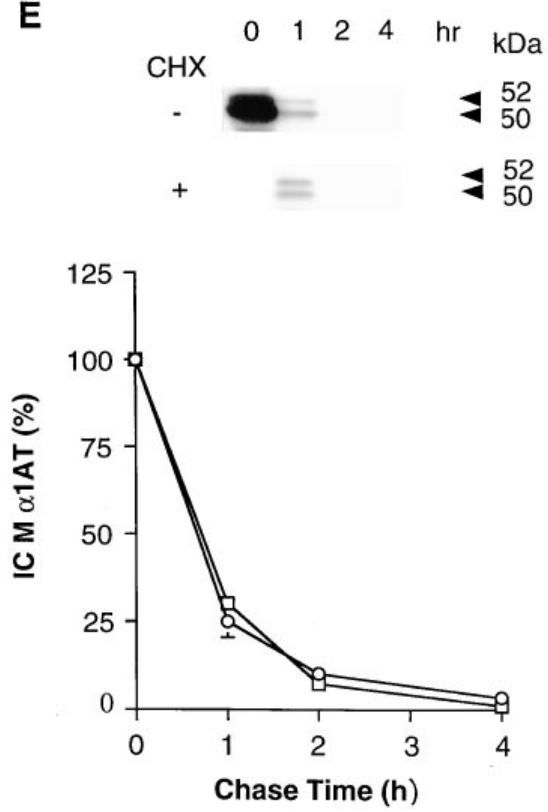

B
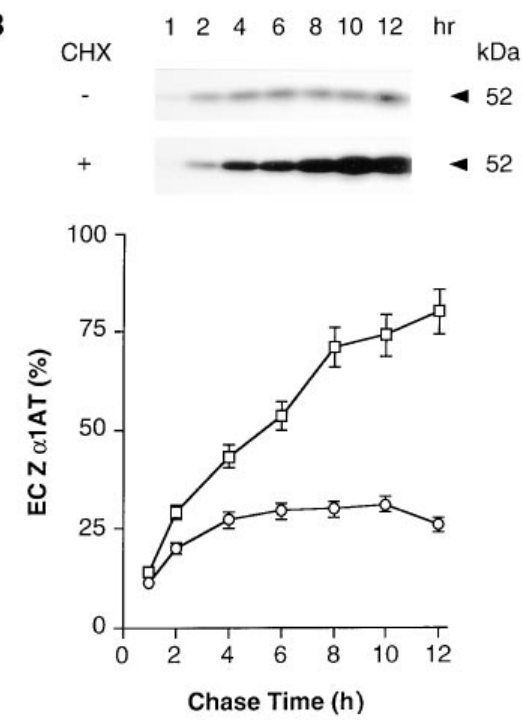

D

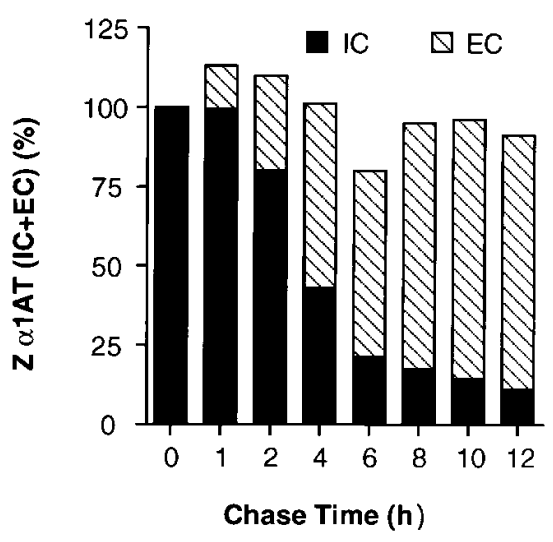

$\mathbf{F}$
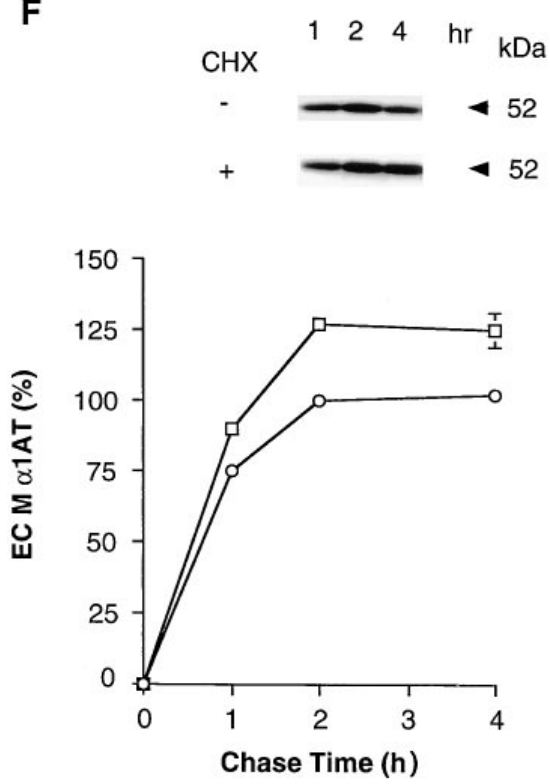

Figure 2. Effect of cycloheximide on vesicular transport of $\alpha 1 \mathrm{AT}$ in $\mathrm{CHO}$ cells. $(A)$ Intracellular $(I C) ;(B)$ extracellular $(E C) ;(C)$ total IC and EC; and $(D)$ total IC and EC after treatment with cycloheximide $\mathrm{Z} \alpha 1 \mathrm{AT}$ at the indicated time of chase were quantified after SDSPAGE. (E) Intracellular $(I C)$ and $(F)$ extracellular $(E C)$ normal $\mathrm{M} \alpha 1 \mathrm{AT}$ at the indicated time of chase was quantified after SDS-

PAGE. Symbols represent percentage of initial radiolabeled $\alpha 1 \mathrm{AT}$ with $(\square)$ and without (O) cycloheximide $(\mathrm{CHX}), 50 \mu \mathrm{g} / \mathrm{ml}$ present during the chase (bars represent the SEM for values of three separate experiments). Inserts (top) are representative SDS-PAGE used for analysis. (Right) Molecular masses (kD) of the fully glycosylated $52-\mathrm{kD}$ and high-mannose $50-\mathrm{kD}$ forms of $\alpha 1 \mathrm{AT}$. 


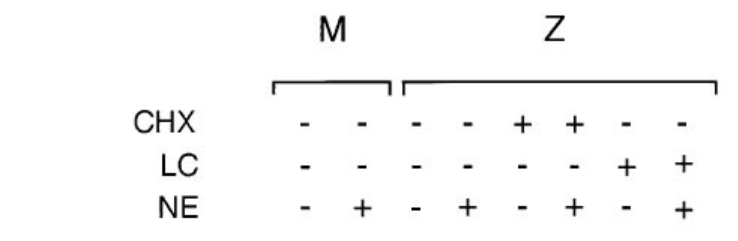

$\mathrm{kDa}$

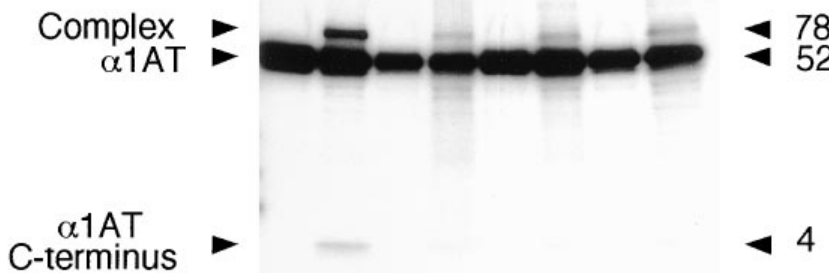

Figure 3. Functional comparison of $\mathrm{M}$ and $\mathrm{Z} \alpha 1 \mathrm{AT}$ with and without cycloheximide or lactacystin treatment. Autoradiogram of SDSPAGE of 78-kD SDS-stable complexes of neutrophil elastase with $\mathrm{M}$ or $\mathrm{Z} \alpha 1 \mathrm{AT}$ secreted by $\mathrm{CHO}$ cells. The formation of SDS-stable neutrophil elastase- $\alpha 1 \mathrm{AT}$ complexes indicates that the secreted $\alpha 1 \mathrm{AT}$ is functionally able to inhibit its major target protease. (Top) Lanes represent secreted $\mathrm{M}$ and $\mathrm{Z} \alpha 1 \mathrm{AT}$ with (+) or without (-) treatment with cycloheximide $(C H X)$ or lactacystin $(L C)$, with $(+)$ or without $(-)$ neutrophil elastase $(N E)$. (Left) Arrows indicate neutrophil elastase- $\alpha 1 \mathrm{AT}$ complexes (Complex), unbound $\alpha 1 \mathrm{AT}(\alpha 1 A T)$, and the $\alpha 1 \mathrm{AT}$ COOH terminus ( $\alpha 1 \mathrm{AT}$ C-terminus) after cleavage of the P1-P1' bond. (Right) apparent molecular masses of 78-, 52-, and $4-\mathrm{kD}$, respectively. Autoradiogram is presented overexposed to demonstrate the 4-kD fragment with a specific activity fivefold less than that of intact $\alpha 1 \mathrm{AT}$ since it contains only 2 of 10 methionines available for radiolabel incorporation.

cence microscopy of CHO cells transfected with $\alpha 1 \mathrm{AT}$ demonstrated a distribution of $\mathrm{Z} \alpha 1 \mathrm{AT}$ that was very different from that of $\mathrm{M} \alpha 1 \mathrm{AT}$. Whereas $\mathrm{M} \alpha 1 \mathrm{AT}$ was concentrated in a perinuclear area, consistent with a predominantly Golgi localization, $\mathrm{Z} \alpha 1 \mathrm{AT}$ was widely dispersed in an RER pattern (Fig. 4, $C-N)$. Treatment with cycloheximide appeared to increase the immunofluorescence of $\mathrm{Z} \alpha 1 \mathrm{AT}$ briefly (presumably by concentrating in the RER and Golgi), and altered its distribution. Importantly, there was no difference in the patterns of localization of $\beta-\mathrm{COP} / \mathrm{p} 58$ or $\mathrm{BiP}$ in untransfected $\mathrm{CHO}$ cells compared with those expressing $\alpha 1 \mathrm{AT}$ (Fig. $4, A-N$ ). Cycloheximide-treated cells demonstrated a dynamic image of $Z \alpha 1 \mathrm{AT}$ vesicular movement, since cycloheximide prevents further translation of $\alpha 1 \mathrm{AT}$. Two $\mathrm{h}$ after cycloheximide treatment, $\mathrm{Z}$ $\alpha 1 \mathrm{AT}$ concentrated in an RER-Golgi pattern. At $6 \mathrm{~h}, \mathrm{Z} \alpha 1 \mathrm{AT}$ had moved into a perinuclear Golgi distribution. By $8 \mathrm{~h}$, there was a significant loss of intracellular immunofluorescence as a result of $\mathrm{Z} \alpha 1 \mathrm{AT}$ secretion (Fig. 4, $O-W$ ). Similarly, treated cells expressing $\mathrm{M} \alpha 1 \mathrm{AT}$ lost their immunofluorescence within 90 min of treatment with cycloheximide (data not shown).

Figure 4. Immunofluorescence photomicrographs showing localization of intracellular $\alpha 1 \mathrm{AT}$ during vesicular transport in $\mathrm{CHO}$ cells. (A) Nontransfected $\mathrm{CHO}$ cells double-labeled with FITC-conjugated anti- $\alpha 1 \mathrm{AT}$ and rhodamine-conjugated antibodies to the RER-resident protein $\mathrm{BiP}$, or $(B)$ Golgi-resident proteins $\beta-\mathrm{COP} / \mathrm{p} 58$, the RER and Golgi complex staining patterns (red), but there was no

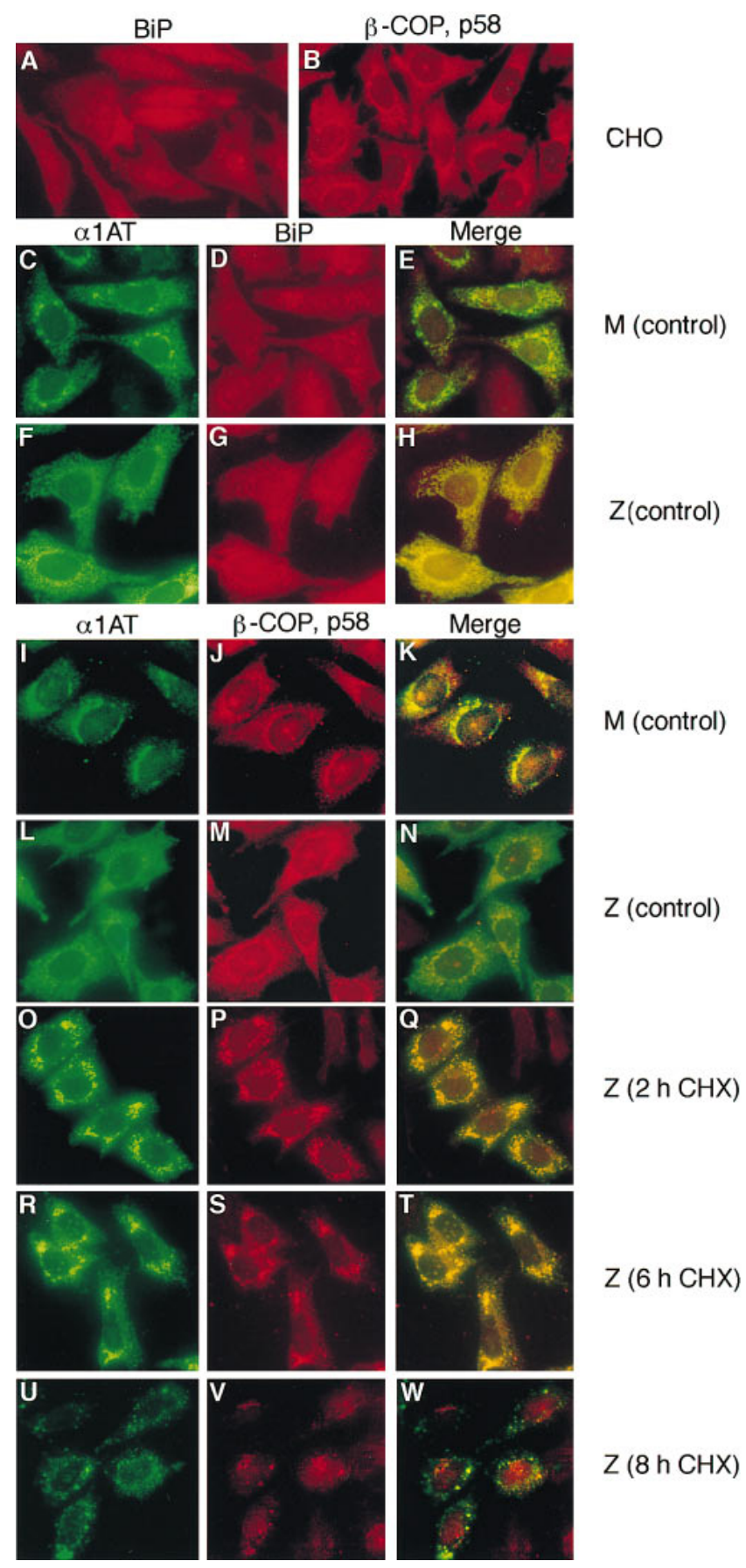

FITC staining detected for $\alpha 1 \mathrm{AT}$ in untransfected cells. $(C-N)$ Untreated $\mathrm{CHO}$ cells expressing $\mathrm{M}$ or $\mathrm{Z} \alpha 1 \mathrm{AT}$ were double-labeled with FITC-conjugated rabbit anti-human $\alpha 1 \mathrm{AT}(C, F, I$, and $L$; green $)$, and $(D$ and $G$ ) rhodamine-conjugated antibodies to the RER-resident protein $\mathrm{BiP}($ red $)$, or Golgi-resident proteins $\beta-\mathrm{COP} / \mathrm{p} 58(J$ and $M ;$ red $)$. Superimposing the red and green images $(E, H, K$, and $N)$ demonstrates colocalization of $\alpha 1 \mathrm{AT}$ with either BiP or $\mathrm{p} 58 / \beta-\mathrm{COP}$ (yellow). ( $O-W) \mathrm{Z} \alpha 1 \mathrm{AT} 2,6$, and $8 \mathrm{~h}$ after treatment with cycloheximide, respectively, double-labeled with FITC- conjugated rabbit anti-human $\alpha 1 \mathrm{AT}(O, R$, and $U$; green $)$ and rhodamine-conjugated antibodies to the Golgi-resident proteins $\beta-\mathrm{COP} / \mathrm{p} 58(P, S$, and $V$; red). Superimposing red and green images demonstrates colocalization of $\alpha 1 \mathrm{AT}$ with $\mathrm{p} 58 / \beta-\mathrm{COP}(Q, T$, and $W$; yellow $)$. The timedependent change in the pattern of $\alpha 1 \mathrm{AT}$ fluorescence in $O-W$ is consistent with normal vesicular movement of $\alpha 1 \mathrm{AT}$ from the RER and secretion into the extracellular milieu. $60 \times$ objective. 

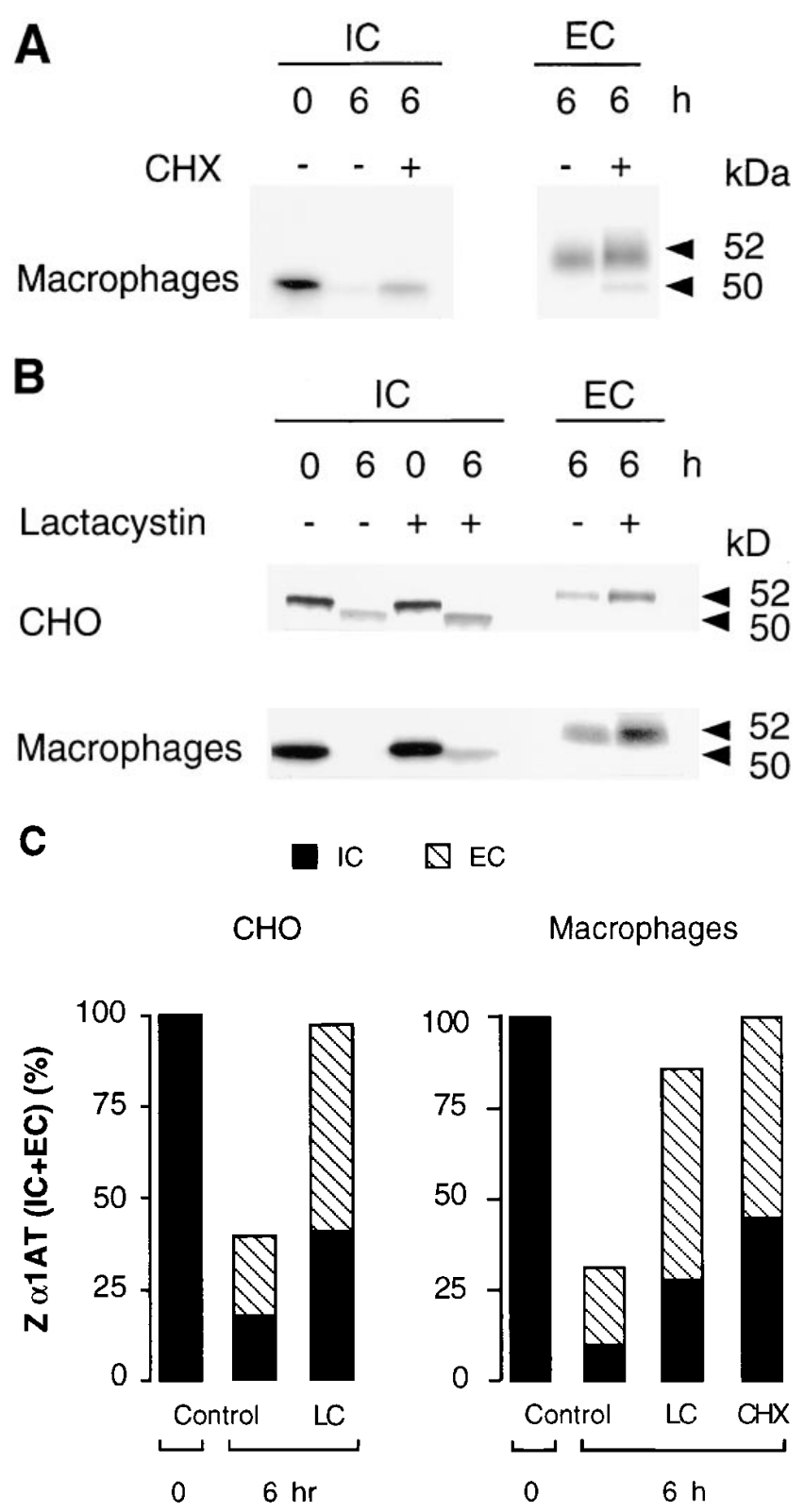

Figure 5. Effect of cycloheximide and the proteasome inhibitor lactacystin on intracellular transport of $\mathrm{Z} \alpha 1 \mathrm{AT}$ in human alveolar macrophages and $\mathrm{CHO}$ cells. $(A)$ Autoradiogram of SDS-PAGE of radiolabeled intracellular $(I C)$ and extracellular $(E C) \mathrm{Z} \alpha 1 \mathrm{AT}$ from human alveolar macrophages (Macrophages). Each lane represents chase time of 0 or $6 \mathrm{~h}$ for IC and $6 \mathrm{~h}$ for EC with (+) or without (-) cycloheximide $(\mathrm{CHX})$. Treatment of alveolar macrophages expressing $\mathrm{Z} \alpha 1 \mathrm{AT}$ with cycloheximide significantly increases intracellular and extracellular $\alpha 1 \mathrm{AT}$ compared with untreated cells. $(B)$ Autoradiogram of SDS-PAGE of radiolabeled IC and EC Z $\alpha 1$ AT from $\mathrm{CHO}$ cells and human alveolar macrophages with $(+)$ or without $(-)$ exposure to $10 \mu \mathrm{M}$ lactacystin at 0 and $6 \mathrm{~h}$ of chase. On the right, arrows indicate the apparent molecular masses $(\mathrm{kD})$ of the fully glycosylated endoglycosidase-H-resistant $52-\mathrm{kD}$ and endoglycosidase$\mathrm{H}$-sensitive high-mannose $50-\mathrm{kD}$ forms of $\alpha 1 \mathrm{AT}$. The $52-\mathrm{kD}$ form of $\alpha 1 \mathrm{AT}$ may be present in both the IC and EC, while the $50-\mathrm{kD}$ form remains in the IC predominantly in the RER. $(C)$ Total intracellular $(I C)$ and extracellular $(E C) \mathrm{Z} \alpha 1 \mathrm{AT}$ at 0 and $6 \mathrm{~h}$ of chase in $\mathrm{CHO}$ and human alveolar macrophages (Macrophages) without (Control) and with lactacystin $(L C)$ or cycloheximide $(C H X)$.
Cycloheximide prevents degradation and increases secretion of $Z$ $\alpha 1 A T$ in alveolar macrophages. Importantly, the effect of cycloheximide on $\mathrm{Z} \alpha 1 \mathrm{AT}$ secretion was not limited to $\alpha 1 \mathrm{AT}$ expressing $\mathrm{CHO}$ cells. When treated with cycloheximide, human alveolar macrophages synthesizing $\mathrm{Z}$ a1AT demonstrated 4.5 \pm 1.0 -fold more intracellular $\mathrm{Z} \alpha 1 \mathrm{AT}(P=0.002)$, and secreted $1.63 \pm 0.13$-fold more $\mathrm{Z} \alpha 1 \mathrm{AT}(P=0.04)$ than did untreated cells after $6 \mathrm{~h}$ of chase (Fig. $5 \mathrm{~A}$ ). The presence of a small amount of the $50-\mathrm{kD} \mathrm{Z} \alpha 1 \mathrm{AT}$ form in the medium after $6 \mathrm{~h}$ of chase is evidence of cycloheximide-induced alveolar macrophage cytotoxicity (Fig. $5 \mathrm{~A}$ ). Since this form corresponds to the high-mannose RER intracellular form of $\alpha 1 \mathrm{AT}$, the $50-\mathrm{kD}$ form of $\alpha 1 \mathrm{AT}$ detected in the medium after treatment of alveolar macrophages was not used to determine the extracellular amount of $\alpha 1 \mathrm{AT}$, since this form was likely not secreted.

Lactacystin increases secretion of $Z$ QlAT in $\mathrm{CHO}$ cells and alveolar macrophages. In contrast to the nonspecific and likely indirect effect of cycloheximide, lactacystin specifically irreversibly inhibits intracellular protein degradation mediated by the multicatalytic complex, i.e., proteasome $(22,26-28)$. Using the proteasome inhibitor lactacystin, degradation of $\mathrm{Z}$ $\alpha 1 \mathrm{AT}$ was substantially inhibited in both $\mathrm{CHO}$ cells and alveolar macrophages. There were no significant differences at time zero between lactacystin-treated and -untreated cells for either CHO cells or alveolar macrophages $(P=0.94$ and $P=0.93$, respectively; Fig. $5 \mathrm{~B}$ ). In $\mathrm{CHO}$ cells, $10 \mu \mathrm{M}$ lactacystin increased intracellular $\mathrm{Z} \alpha 1 \mathrm{AT}$ by $1.69 \pm 0.33$-fold $(P=0.03)$ and secreted $\mathrm{Z} \alpha 1 \mathrm{AT}$ by $1.86 \pm 0.13$-fold $(P=0.03)$ after $6 \mathrm{~h}$ of chase (Fig. 5 B). Pretreatment with $2 \mu \mathrm{g} / \mathrm{ml}$ brefeldin A prevented lactacystin's inhibitory effect on $\mathrm{Z} \alpha 1 \mathrm{AT}$ intracellular degradation ( $\mathrm{Z} \alpha 1 \mathrm{AT}$ half-lives were $\sim 10 \mathrm{~h}$ with or without lactacystin). The additional secreted $\mathrm{Z} \alpha 1 \mathrm{AT}$ was functional since it formed SDS-stable complexes with neutrophil elastase in proportions similar to $\mathrm{Z} \alpha 1 \mathrm{AT}$ from untreated cells (Fig. 3). Interestingly, $10 \mu \mathrm{M}$ lactacystin treatment also increased $\mathrm{M}$ $\alpha 1 \mathrm{AT}$ secretion by amounts similar to those of cycloheximide (data not shown).

In human alveolar macrophages, lactacystin increased intracellular $\mathrm{Z} \alpha 1$ AT by $2.79 \pm 0.33$-fold $(P=0.045)$ and secreted $\mathrm{Z} \alpha 1 \mathrm{AT}$ by $1.76 \pm 0.24$-fold $(P=0.025)$ under similar conditions (Fig. $5 \mathrm{~B}$ ). Comparison of the total intra- and extracellular $\alpha 1 \mathrm{AT}$ at time points after synthesis of the radiolabeled $\alpha 1 \mathrm{AT}$ was completed demonstrated that $>60 \%$ of the newly synthesized $\alpha 1 \mathrm{AT}$ was exported to the extracellular compartment in the presence of lactacystin after $6 \mathrm{~h}$ of chase. In the absence of lactacystin, $\sim 25 \%$ of the synthesized $\mathrm{Z} \alpha 1 \mathrm{AT}$ is exported extracellularly (Fig. $5 \mathrm{C}$ ). Alveolar macrophages treated with either lactacystin or cycloheximide demonstrated similar, but not identical, results to transfected $\mathrm{CHO}$ cells (Fig. $5 C)$.

Consistent with this observation, studies of intracellular localization using immunofluorescence microscopy demonstrated that lactacystin concentrated $\mathrm{Z} \alpha 1 \mathrm{AT}$ and altered its distribution in $\mathrm{CHO}$ cells from a predominantly RER to a mixed Golgi-RER pattern (Fig. 6), similar to that in cells treated with cycloheximide for $2 \mathrm{~h}$ (compared with Fig. 4, $O-Q$ ). It was not possible to determine accurately the intracellular location of $\alpha 1 \mathrm{AT}$ in human alveolar macrophages by immunofluorescence microscopy because of their inherent autofluorescence (25). 

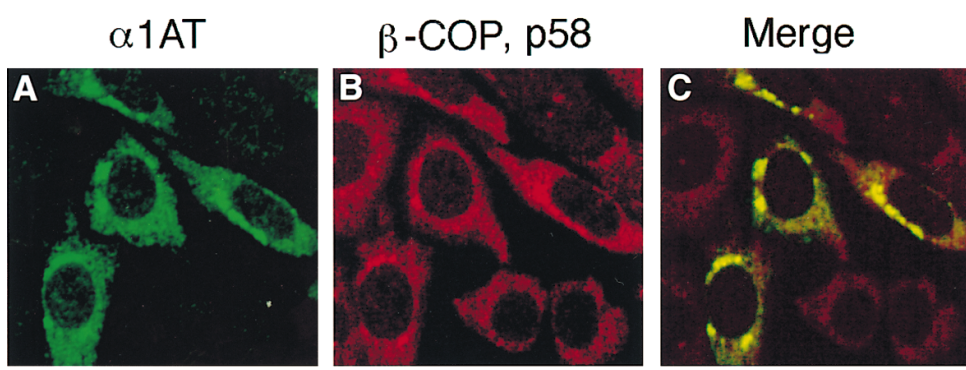
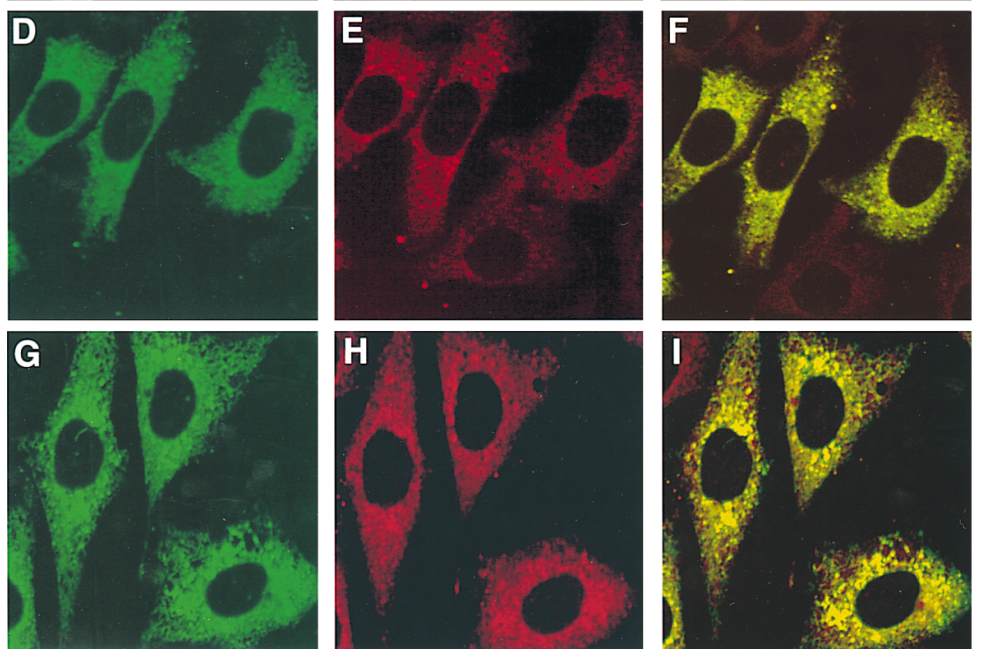

\section{M (control)}

Figure 6. Confocal photomicrographs show immunofluorescence localization of intracellular $\mathrm{Z} \alpha 1 \mathrm{AT}$ during vesicular transport in $\mathrm{CHO}$ cells with and without treatment with $10 \mu \mathrm{M}$ lactacystin. ( $A, D$, and $G) \mathrm{M}$ and $\mathrm{Z} \alpha 1 \mathrm{AT}$-transfected $\mathrm{CHO}$ cells were double-labeled with FITC-conjugated rabbit antihuman $\alpha 1 \mathrm{AT}$ (green) and $(B, E$, and $H)$ rhodamine-conjugated antibodies to the Golgi-resident proteins $\beta-\mathrm{COP} / \mathrm{p} 58$ (red). (C) Colocalization of the green and red labels shows that $\mathrm{M} \alpha 1 \mathrm{AT}$ is concentrated in the Golgi (yellow). (F) Z $\alpha 1 \mathrm{AT}$ untreated (control) cells have a diffuse pattern with no concentration in the

\section{Z (lactacystin)} Golgi (small amount of yellow). (I)

After $6 \mathrm{~h}$ of treatment with lactacystin (lactacystin), Z $\alpha 1 \mathrm{AT}$ demonstrate a mixed Golgi and presumably, RER pattern (increased yellow). $100 \times$ objective.

\section{Discussion}

The concept of defective protein folding as a basis of some human diseases has gained attention, particularly among laboratories investigating cystic fibrosis and $\alpha 1 \mathrm{AT}$ deficiency $(4,8$, 29-33). Much of this interest is based on the fact that our understanding of the mechanisms for processing misfolded proteins has been substantially extended $(34,35)$. In this study, we used a model $\mathrm{CHO}$ cell system and human alveolar macrophages expressing $\mathrm{Z} \alpha 1 \mathrm{AT}$, a variant associated with misfolding and $\alpha 1 \mathrm{AT}$ deficiency, to determine the effect of inhibition of intracellular degradation on its vesicular transport.

Using this model system, we demonstrated that $\mathrm{Z} \alpha 1 \mathrm{AT}$ was secreted in amounts four to sixfold less than those of normal M $\alpha 1 \mathrm{AT}$. This reduction in secreted $\alpha 1 \mathrm{AT}$ correlates well with $\alpha 1 \mathrm{AT}$ levels observed in $\alpha 1 \mathrm{AT}$-deficient individuals (1). Furthermore, the bulk of $\mathrm{Z} \alpha 1 \mathrm{AT}$ was retained in the RER/ pre-Golgi compartment and degraded, since most intracellular $\mathrm{Z} \alpha 1 \mathrm{AT}$ is endoglycosidase $\mathrm{H}$-sensitive and colocalizes with the RER resident protein, BiP. One potential limitation of the $\mathrm{CHO}$ cell model may be that overproduction of a protein that is not normally expressed may alter protein-trafficking characteristics in a manner that does not reflect the natural mechanisms of protein transport. Therefore, observations made in such a model system should be interpreted with caution. In this context, it is critical that the model system share features of protein transport that are similar to those of cells that normally express $\alpha 1 \mathrm{AT}$ (hepatocytes or alveolar macrophages).

Degradation of $\mathrm{Z} \alpha 1 \mathrm{AT}$ was prevented by adding the metabolic poisons cycloheximide and lactacystin. The effect of metabolic poisons and cycloheximide on intracellular catabolism of $\mathrm{Z} \alpha 1 \mathrm{AT}$ is likely indirect and nonspecific. Lactacystin causes direct inhibition of intracellular degradation of $\mathrm{Z}$ $\alpha 1 \mathrm{AT} . \mathrm{Z} \alpha 1 \mathrm{AT}$ intracellular degradation was not affected by brefeldin A or inhibitors of lysosomal function. These observations are consistent with previous studies in several in vitro systems $(5,10,12,14-18)$. There was a substantial difference in the rate of intracellular degradation of $\mathrm{M}$ and $\mathrm{Z} \alpha 1 \mathrm{AT}$ in the presence of brefeldin A (24 vs. $10 \mathrm{~h}$, respectively). Since Z $\alpha 1 \mathrm{AT}$ is known to misfold and forms polymers in the RER, the different intracellular half-lives of $\mathrm{M}$ and $\mathrm{Z} \alpha 1 \mathrm{AT}$ suggest either that $\mathrm{Z} \alpha 1 \mathrm{AT}$ is degraded by another pathway, or that there exists preferential degradation of the misfolded protein $(4,36)$. The observation that only $50-60 \%$ of $\mathrm{Z} \alpha 1 \mathrm{AT}$ is degraded by an energy-dependent process provides further evidence that at least one other pathway participates in the degradation of $\mathrm{Z} \alpha 1 \mathrm{AT}$. Since intracellular $\mathrm{Z} \alpha 1 \mathrm{AT}$ accumulated very rapidly after adding cycloheximide or puromycin, very short-lived protein(s) seem to play an essential role in $\mathrm{Z} \alpha 1 \mathrm{AT}$ degradation.

We conclude that $\mathrm{Z} \alpha 1 \mathrm{AT}$ degradation in our model $\mathrm{CHO}$ cell system is mediated by both energy-dependent and energyindependent nonserine, nonlysosomal processes, and requires a very short-lived protein component(s). These findings resemble those of Le et al. $(12,15)$, who used a rat hepatocyte model system.

Recent work by $\mathrm{Qu}$ and colleagues has demonstrated that $\mathrm{Z} \alpha 1 \mathrm{AT}$ binds to the luminal domain of calnexin, while its cytoplasmic domain becomes ubiquitinated and degraded by proteasomes $(18,37)$. Since a significant proportion of $\mathrm{Z} \alpha 1 \mathrm{AT}$ $(40-50 \%)$ is also degraded in an energy-independent fashion, ubiquitination-proteasome-mediated proteolysis is not the sole pathway for intracellular $\mathrm{Z} \alpha 1 \mathrm{AT}$ degradation $(23,24,27$, 38). Nevertheless, proteasomes clearly mediate the bulk of in- 
tracellular $\mathrm{Z} \alpha 1 \mathrm{AT}$ degradation since lactacystin prevented $\mathrm{Z}$ $\alpha 1 \mathrm{AT}$ degradation in CHO cells and transfected human fibroblasts (18). These findings are consistent with lactacystin's known inhibition of proteasome function, which would reduce intracellular degradation of $\mathrm{Z} \alpha 1 \mathrm{AT}$.

In addition to preventing intracellular degradation, cycloheximide and lactacystin significantly increased secretion of $\mathbf{Z}$ $\alpha 1 \mathrm{AT}$ in $\mathrm{CHO}$ cells and human alveolar macrophages. Cycloheximide- or lactacystin-treated $\mathrm{CHO}$ cells expressing $\mathrm{M}$ $\alpha 1$ AT secreted $25-43 \%$ more $\alpha 1$ AT compared with untreated cells, an observation that suggests ongoing degradation of a portion of the $\mathrm{M} \alpha 1 \mathrm{AT}$ intracellular pool.

Comparison of the total intra- and extracellular $\alpha 1 \mathrm{AT}$ at time points after radiolabeled $\alpha 1 \mathrm{AT}$ synthesis was completed, demonstrated that $>80 \%$ of the newly synthesized $\alpha 1 \mathrm{AT}$ is eventually exported to the extracellular compartment in the presence of cycloheximide. In the absence of cycloheximide, $\sim 25 \%$ of the synthesized $\mathrm{Z} \alpha 1 \mathrm{AT}$ is exported extracellularly. Loss of $55 \%$ of the synthesized $\mathrm{Z} \alpha 1 \mathrm{AT}$ in the absence of cycloheximide could only be the result of intracellular degradation, since only a small proportion of total labeled $\alpha 1 \mathrm{AT}$ remains in the intracellular compartment at the end of the chase period. Delay in secretion of $\mathrm{Z} \alpha 1 \mathrm{AT}$ after inhibition of intracellular degradation is likely due to the increased time required for misfolded $\mathrm{Z} \alpha 1 \mathrm{AT}$ to dissociate into the monomeric form and/or to recycle through the vesicular transport system $(34,39)$.

While direct evidence of cycloheximide's inhibition of intracellular degradation cannot be provided, most of the accumulated $\mathrm{Z} \alpha 1 \mathrm{AT}$ exited the cell. This interpretation of the data is supported by the changing pattern of subcellular localization of $\alpha 1 \mathrm{AT}$ immunofluorescence over time in $\mathrm{CHO}$ cells treated with cycloheximide. Since cycloheximide prevents further translation of $\alpha 1 \mathrm{AT}$, time course experiments that follow $\mathrm{Z}$ $\alpha 1 \mathrm{AT}$ subcellular localization after cycloheximide treatment present a dynamic picture of its movement from its site of retention in the RER to secretion into the extracellular compartment. In comparison to the nonspecific effect of cycloheximide on $\mathrm{Z} \alpha 1 \mathrm{AT}$ intracellular catabolism, treatment with lactacystin specifically interferes with $\mathrm{Z} \alpha 1 \mathrm{AT}$ degradation by inhibiting proteasome function $(18,22,26-28,37)$. Therefore, the mixed RER/Golgi pattern of $\mathrm{Z} \alpha 1 \mathrm{AT}$ immunofluorescence after treatment with lactacystin represents a new subcellular steady state. This pattern is in contrast with that observed in $\mathrm{M}$ $\alpha 1 \mathrm{AT}$-synthesizing $\mathrm{CHO}$ cells that have a predominant Golgi pattern of immunofluorescence, since unlike polymerized $\mathrm{Z}$ $\alpha 1 \mathrm{AT}$, normal unpolymerized $\mathrm{M} \alpha 1 \mathrm{AT}$ moves quickly from the RER to the Golgi. By preventing intracellular degradation, lactacystin and cycloheximide allow $\mathrm{Z} \alpha 1 \mathrm{AT}$ to become concentrated within the RER. The Z $\alpha 1 \mathrm{AT}$ then slowly enters the vesicular transport system, i.e., moves to the Golgi and beyond. In contrast to specific proteasome inhibitors, cycloheximide likely has no application as a potential therapeutic approach for treating diseases associated with retained mutant protein degradation.

$\mathrm{Z} \alpha 1 \mathrm{AT}$ secreted by cells treated with cycloheximide or lactacystin had a similar capacity to form SDS-stable complexes with neutrophil elastase as $\mathrm{Z} \alpha 1 \mathrm{AT}$ from untreated cells. The capacity of $\mathrm{Z} \alpha 1 \mathrm{AT}$ to form complexes with neutrophil elastase was half that of $\mathrm{M} \alpha 1 \mathrm{AT}$. This finding is consistent with previous studies demonstrating that $\mathrm{Z}$ is half as functional as $\mathrm{M} \alpha 1 \mathrm{AT}$ (40). It is possible that cycloheximide or lactacystin could alter the specificity of intracellular $\alpha 1 \mathrm{AT}$ transport such that polymers of $\alpha 1 \mathrm{AT}$ were exported. Z $\alpha 1 \mathrm{AT}$ polymers form by reactive site loop incorporation into the $\beta$ sheet of another molecule. The function of such $\alpha 1 \mathrm{AT}$ polymers would be very low in proportion to the amount of antigenic $\alpha 1 \mathrm{AT}$ detected because their reactive loops would be unavailable for interaction with neutrophil elastase. Release of intracellular polymer cannot account for the appearance of increased $\alpha 1 \mathrm{AT}$ in the medium since the proportion of $\mathrm{Z} \alpha 1 \mathrm{AT}$ neutrophil elastase complexes in treated and untreated cells is similar.

Although cycloheximide and lactacystin almost completely inhibited intracellular catabolism of $\mathrm{Z} \alpha 1 \mathrm{AT}$, pretreatment with brefeldin A abolished their effect on its intracellular degradation. However, in the context that $\alpha 1 \mathrm{AT}$ folding and degradation normally occur in the RER and pre-Golgi compartments, this finding must be interpreted cautiously since brefeldin $\mathrm{A}$ is known to disrupt these structures $(12,15,41)$. Thus, it is possible that brefeldin A abolishes the effects of cycloheximide and lactacystin on intracellular degradation of $\mathbf{Z}$ $\alpha 1 \mathrm{AT}$ only when the compartment contents are mixed, and therefore does not reflect the normal processing of $\mathrm{Z} \alpha 1 \mathrm{AT}$.

In this context, increased secretion of $\mathrm{Z} \alpha 1 \mathrm{AT}$ after inhibition of degradation can be explained as follows: (a) Misfolded $\mathrm{Z} \alpha 1 \mathrm{AT}$ molecules that polymerize by loop-sheet linkage cannot exit the RER because their polymer size prevents their inclusion transport vesicles $(7,8)$. (b) This delay in transport increases the opportunity for a misfolded protein to be either targeted for degradation or retrieved to the vesicular traffic pathway via chaperones such as calnexin $(12,15,34,37,42,43)$. (c) When proteasome function is inhibited, degradation ceases and only retrieval via vesicular trafficking occurs (26). The observation that inhibition of intracellular degradation of $\mathrm{Z}$ $\alpha 1 \mathrm{AT}$ allows apparently normal vesicular trafficking supports the contention of Le et al. that very little $\mathrm{Z} \alpha 1 \mathrm{AT}$ exists in an insoluble form within the RER. Therefore, the bulk of intracellular $\mathrm{Z} \alpha 1 \mathrm{AT}$ remains available in a soluble form for either degradation or transport to another intracellular compartment $(12,15)$.

The therapeutic potential of proteasome inhibitors in rescuing misfolded proteins depends upon the functional capacity of the rescued protein and the importance of proteasome function for other processes, such as in regulating cytokines and modulating immune processes involving antigen presentation. $(24,26,27)$. In considering the application of this approach to the treatment of $\alpha 1 \mathrm{AT}$ deficiency, it is important to recognize that $\mathrm{Z} \alpha 1 \mathrm{AT}$ secreted by alveolar macrophages is likely partially functional. Furthermore, the magnitude of the enhanced secretion that we observed was less than twofold in alveolar macrophages at $6 \mathrm{~h}$ compared with approximately threefold in CHO cells; thus, not all types of cell secrete similarly increased amounts of $\alpha 1 \mathrm{AT}$. Nevertheless, the finding that inhibition of intracellular $\alpha 1 \mathrm{AT}$ degradation increases delivery of $\alpha 1 \mathrm{AT}$ to the extracellular milieu provides a new potential treatment of $\alpha 1 \mathrm{AT}$ deficiency and other diseases associated with misfolded proteins $(29,30)$.

\section{Acknowledgments}

We thank F. Rouhani for help in isolating human alveolar macrophages, Drs. M. Vaughan and W. Gahl for reviewing the manuscript, and Drs. Yewdell and Neckers for their gift of lactacystin. 
This work was supported by National Institutes of Health National Blood, Heart, and Lung Institute intramural funding.

\section{References}

1. Blank, C.A., and M. Brantly. 1994. Clinical features and molecular characteristics of alpha 1-antitrypsin deficiency. Ann. Allergy. 72:105-120.

2. Cox, D. 1995. $\alpha 1$-Antitrypsin deficiency. In The Metabolic Basis of Inherited Disease. C. Scriver, A. Beaudet, W. Sly, and D. Valle, editors. McGrawHill, New York. 4125-4158.

3. Brantly, M. 1996. Alpha-1-antitrypsin genotypes and phenotypes. In Alpha-1-Antitrypsin Deficiency: Biology, Pathogenesis, Clinical Manifestations and Therapy. Vol. 88. R.G. Crystal, editor. Marcel Dekker, Inc., New York. 4560 .

4. Yu, M.H., K.N. Lee, and J. Kim. 1995. The Z type variation of human alpha 1-antitrypsin causes a protein folding defect. Nat. Struct. Biol. 2:363-367.

5. Brantly, M., M. Courtney, and R.G. Crystal. 1988. Repair of the secretion defect in the $\mathrm{Z}$ form of alpha 1-antitrypsin by addition of a second mutation. Science. 242:1700-1702.

6. Sifers, R.N., M.J. Finegold, and S.L. Woo. 1992. Molecular biology and genetics of alpha 1-antitrypsin deficiency. Semin. Liver Dis. 12:301-310.

7. Lomas, D., D. Evans, J. Finch, and R. Carrell. 1992. The mechanism of Z alpha1-antitrypsin accumulation in the liver. Nature. 357:605-607.

8. Lomas, D.A. 1994. Loop-sheet polymerization: the structural basis of $\mathrm{Z}$ Alpha1-antitrypsin accumulation in the liver. Clin. Sci. 86:489-495.

9. Sifers, R.N. 1992. Protein transport. Z and the insoluble answer. Nature. 357:541-542

10. Ciccarelli, E., M.A. Alonso, D. Cresteil, A. Bollen, P. Jacobs, and F. Alvarez. 1993. Intracellular retention and degradation of human mutant variant of a alpha 1-antitrypsin in stably transfected Chinese hamster ovary cell lines. Eur. J. Biochem. 213:271-276.

11. Brodbeck, R.M., and J.L. Brown. 1992. Secretion of alpha-1-proteinase inhibitor requires an almost full length molecule. J. Biol. Chem. 267:294-297.

12. Le, A., K.S. Graham, and R.N. Sifers. 1990. Intracellular degradation of the transport-impaired human PiZ alpha 1-antitrypsin variant. Biochemical mapping of the degradative event among compartments of the secretory pathway. J. Biol. Chem. 265:14001-14007.

13. Perlmutter, D.H., F.S. Cole, P. Kilgridge, T.H. Rossing, and H.R. Colten. 1985. Expression of the alpha1-proteinase inhibitor gene in human monocytes and macrophages. Proc. Natl. Acad. Sci. USA. 82:795-799.

14. McCracken, A., K. Kruse, and J. Brown. 1989. Molecular basis for defective secretion of the A variant of human alpha-1-protease inhibitor: secretion variants having altered potential for salt bridge formation between amino acids 290 and 342. Mol. Cell. Biol. 9:1406-1414.

15. Le, A., G.A. Ferrell, D.S. Dishon, Q.Q. Le, and R.N. Sifers. 1992. Soluble aggregates of the human PiZ alpha 1-antitrypsin variant are degraded within the endoplasmic reticulum by a mechanism sensitive to inhibitors of protein synthesis. J. Biol. Chem. 267:1072-1080.

16. Perlmutter, D.H., R.M. Kay, S. Cole, T.H. Rossing, D. Van Thiel, and H.R. Colten. 1985. The cellular defect in alpha-1-proteinase inhibitor (alpha1PI) deficiency is expressed in human monocytes and in Xenopus oocytes injected with human liver mRNA. Proc. Natl. Acad. Sci. USA. 82:6918-6921.

17. Perlmutter, D.H., R.M. Kay, S. Cole, T.H. Rossing, D. Van Thiel, and H.R. Colten. 1985. A selective defect in secretion of alpha1-proteinase inhibitor PiZZ demonstrated in surrogate and primary extrahepatic cell culture. Trans. Assoc. Am. Phys. 98:47-54.

18. Qu, D., J. Teckman, S. Omura, and D. Perlmutter. 1996. Degradation of a mutant secretory protein, $\alpha 1$-antitrypsin $\mathrm{Z}$, in the endoplasmic reticulum requires proteasome activity. J. Biol. Chem. 271:22791-22795.

19. Brantly, M.L., J.-H. Lee, J. Hildeshiem, C.-S. Uhm, U.B.S. Prakash, B.A. Staats, and R.G. Crystal. 1997. $\alpha 1$-Antitrypsin gene mutation hotspot associated with the formation of a retained and degraded null variant. Am. J. Respir. Cell Mol. Biol. 16:225-231.

20. Laubach, V., J. Ryan, and M. Brantly. 1993. Characterization of a human $\alpha 1$-antitrypsin null allele involving aberrant mRNA splicing. Hum. Mol. Genet. 2:1001-1005.
21. Lippincott-Schwartz, J., J.S. Bonifacino, L.C. Yuan, and R.D. Klausner. 1988. Degradation from the endoplasmic reticulum: disposing of newly synthesized proteins. Cell. 54:209-220.

22. Fenteany, G., R.F. Standaert, W.S. Lane, S. Choi, E.J. Corey, and S.L. Schreiber. 1995. Inhibition of proteasome activities and subunit-specific aminoterminal threonine modification by lactacystin. Science. 268:726-731.

23. Jensen, T.J., M.A. Loo, S. Pind, D.B. Williams, A.L. Goldberg, and J.R. Riordan. 1995. Multiple proteolytic systems, including the proteasome, contribute to CFTR processing. Cell. 83:129-135.

24. Palombella, V.J., O.J. Rando, A.L. Goldberg, and T. Maniatis. 1994 The ubiquitin-proteasome pathway is required for processing the NF-kappa B1 precursor protein and the activation of NF-kappa B. Cell. 78:773-785.

25. Lohmeyer, J., J. Friedrich, S. Rosseau, H. Pralle, and W. Seeger. 1994. Multiparameter flow cytometric analysis of inflammatory cells contained in bronchoalveolar lavage fluid. J. Immunol. Methods. 172:59-70.

26. Rock, K.L., C. Gramm, L. Rothstein, K. Clark, R. Stein, L. Dick, D. Hwang, and A.L. Goldberg. 1994. Inhibitors of the proteasome block the degradation of most cell proteins and the generation of peptides presented on MHC class I molecules. Cell. 78:761-771.

27. Goldberg, A.L. 1995. Functions of the proteasome: the lysis at the end of the tunnel. Science. 268:522-523.

28. Goldberg, A.L., and A.C. St. John. 1976. Intracellular protein degradation in mammalian and bacterial cells: part 2. Annu. Rev. Biochem. 45:747-803.

29. Thomas, P.J., B.H. Qu, and P.L. Pedersen. 1995. Defective protein folding as a basis of human disease. Trends Biochem. Sci. 20:456-459.

30. Sifers, R.N. 1995. Defective protein folding as a cause of disease. Nat. Struct. Biol. 2:355-357.

31. Sato, S., C.L. Ward, M.E. Krouse, J.J. Wine, and R.R. Kopito. 1996 Glycerol reverses the misfolding phenotype of the most common cystic fibrosis mutation. J. Biol. Chem. 271:635-638.

32. Ward, C.L., and R.R. Kopito. 1994. Intracellular turnover of cystic fibrosis transmembrane conductance regulator. Inefficient processing and rapid degradation of wild-type and mutant proteins. J. Biol. Chem. 269:25710-25718.

33. Gunderson, K.L., and R.R. Kopito. 1995. Conformational states of CFTR associated with channel gating: the role ATP binding and hydrolysis. Cell. 82:231-239.

34. Hammond, C., and A. Helenius. 1995. Quality control in the secretory pathway. Curr. Opin. Cell Biol. 7:523-529.

35. Klausner, R.D., and R. Sitia. 1990. Protein degradation in the endoplasmic reticulum. Cell. 62:611-614.

36. Yu, M.H., K.N. Lee, J. Kim, and K.S. Kwon. 1994. Stability of native alpha-1-antitrypsin as probed by single amino acid substitutions that confer enhancement in stability. J. Cell. Biochem. 180(Abstr.):164.

37. Le, A., J.L. Steiner, G.A. Ferrell, J.C. Shaker, and R.N. Sifers. 1994. Association between calnexin and a secretion-incompetent variant of human alpha 1-antitrypsin. J. Biol. Chem. 269:7514-7519.

38. Sawada, H., K. Muto, M. Fujimuro, T. Akaishi, M.T. Sawada, H. Yokosawa, and A.L. Goldberg. 1993. Different ratios in $20 \mathrm{~S}$ proteasomes and regulatory subunit complexes in two isoforms of the $26 \mathrm{~S}$ proteasome purified from rabbit skeletal muscle. FEBS Lett. 335:207-212.

39. Choudhury, P., Y. Liu, R.J. Bick, and R.N. Sifers. 1997. Intracellular association between UDP-glucose:glycoprotein glucosyltransferase and an incompletely folded variant of alpha1-antitrypsin. J. Biol. Chem. 272:1344613451.

40. Ogushi, F., G.A. Fells, R.C. Hubbard, S.D. Straus, and R.G. Crystal 1987. Z-type alpha 1-antitrypsin is less competent than M1-type alpha 1-antitrypsin as an inhibitor of neutrophil elastase. J. Clin. Invest. 80:1366-1374.

41. Lippincott-Schwartz, J., L.C. Yuan, J.S. Bonifacino, and R.D. Klausner 1989. Rapid redistribution of Golgi proteins into the ER in cells treated with brefeldin A: evidence for membrane cycling from Golgi to ER. Cell. 56:801813.

42. Liu, Y., P. Choudhury, C.M. Cabral, and R.N. Sifers. 1997. Intracellular disposal of incompletely folded human alpha1-antitrypsin involves release from calnexin and post-translational trimming of asparagine-linked oligosaccharides. J. Biol. Chem. 272:7946-7951.

43. Ou, W.J., P.H. Cameron, D.Y. Thomas, and J.J. Bergeron. 1993. Association of folding intermediates of glycoproteins with calnexin during protein maturation. Nature. 364:771-776. 